\section{Revisiting the Risk of Intraparenchymal Hemorrhage following Aneurysm Treatment by Flow Diversion}

We read with interest the recent case series by Cruz et al, ${ }^{1}$ reporting their experience with the Pipeline Embolization Device (PED; Chestnut Medical Technologies, Menlo Park, California) in 66 patients with 47 anterior circulation aneurysms. The emphasis of this article was on the high rate of delayed (1-6 days postprocedure) ipsilateral intraparenchymal hemorrhage (IPH) in 4 of 47 patients (8.5\%). The authors proposed that these adverse events are unlikely secondary to aneurysm characteristics or intraprocedural events but are rather due to hemodynamic changes and altered arterial compliance of the parent vessel caused by the PED.

What is most alarming, the rate of IPH in this series by Cruz et $\mathrm{al}^{1}$ is significantly higher than that in all other large series of PED embolizations published to date. A recent review by Fargen et $\mathrm{al}^{2}$ of complications associated with the PED from 7 large series reported a total IPH count of 4 in 374 patients treated (1.1\%). This rate is in line with the annual risk of dual antiplatelet therapy alone, ${ }^{3}$ when used for secondary stroke prevention, ${ }^{4}$ and lower than the IPH rate of $2.2 \%$ reported after stent-assisted coiling. ${ }^{5}$ The article by Fargen et al did not include our recently published series of 34 patients, in which there were no instances of IPH. ${ }^{6}$ To date, we have treated 56 patients with 68 aneurysms (60 anterior circulation, 8 posterior circulation) with no ICH events $(0 \%)$. If we add our results to the data compiled for the article by Fargen et al, there are a total of $4 \mathrm{ICH}$ events in 430 treated patients, or $0.9 \%$. This rate is 10 -fold lower than that reported by Cruz et al.

As described above, various mechanisms have been proposed to explain IPH after PED embolization. Given the variable rates of IPH in the literature, it is unlikely that these events are intrinsic to the PED itself. Alterations in parent vessel compliance and hemodynamics also do not fully explain these events because IPH rates should be more uniform across multiple series. If changes in vessel compliance from the PED increased the risk of IPH, implantation of longer length devices or telescoped multidevice constructs should result in more cases of IPH. This has not been observed in the published literature or in our personal series. ${ }^{6}$

We have stressed that the PED is not simply a device but rather a set of complex, customizable techniques. ${ }^{6,7}$ Vessel manipulation during PED treatment can be substantial in certain cases, particularly when establishing robust proximal access and during PED deployment in tortuous vessels. Great care must be taken at multiple steps to avoid iatrogenic embolic events, endothelial injury, and significant vasospasm - all of which can cause stroke and have the potential for hemorrhagic conversion. Avoidance and reduction of adverse outcomes requires careful attention to patient selection, user technique, and postprocedure management. These variables should be at the forefront of any discussion of adverse outcomes, particularly when there is a discrepancy between the outcomes achieved at different centers. Flow diversion for treatment of aneurysms is still in its infancy, and discussions such as this about outcomes and techniques are important to further improve and optimize treatment paradigms for our patients.

\section{References}

1. Cruz JP, Chow M, O'Kelly C, et al. Delayed ipsilateral parenchymal hemorrhage following flow diversion for the treatment of anterior circulation aneurysms. AJNR Am J Neuroradiol 2012;33:603-08

2. Fargen KM, Velat GJ, Lawson MF, et al. Review of reported complications associated with the Pipeline embolization device. World Neurosurg 2012;77: 403-04

3. Serebruany VL, Malinin AI, Ferguson JJ, et al. Bleeding risks of combination vs. single antiplatelet therapy: a meta-analysis of 18 randomized trials comprising 129,314 patients. Fundam Clin Pharmacol 2008;22:315-21

4. Diener HC, Bogousslavsky J, Brass LM, et al. Aspirin and clopidogrel compared with clopidogrel alone after recent ischaemic stroke or transient ischaemic attack in high-risk patients (MATCH): randomised, double-blind, placebocontrolled trial. Lancet 2004;364:331-37

5. Shapiro M, Becske T, Sahlein D, et al. Stent-supported aneurysm coiling: a literature survey of treatment and follow-up. AJNR Am J Neuroradiol 2012;33:159-63

6. Colby GP, Lin LM, Gomez JF, et al. Immediate procedural outcomes in 35 consecutive Pipeline embolization cases: a single-center, single-user experience. J Neurointerv Surg 2012 Mar 29. [Epub ahead of print]

7. Colby GP, Gomez JF, Lin LM, et al. In situ removal of the Pipeline embolization device: the 'corking' and 'pseudo-corking' techniques. J Neurointerv Surg 2012 Feb 23. [Epub ahead of print]

$$
\begin{array}{r}
\text { G.P. Colby } \\
\text { L.-M. Lin } \\
\text { A.L. Coon } \\
\text { Department of Neurosurgery } \\
\text { Johns Hopkins University School of Medicine } \\
\text { The Johns Hopkins Hospital } \\
\text { Baltimore, Maryland }
\end{array}
$$

http://dx.doi.org/10.3174/ajnr.A3201 